\title{
Application of a geographical information system approach for risk analysis of fascioliasis in southern Espírito Santo state, Brazil
}

\author{
Isabella Vilhena Freire Martins ${ }^{1}$, Barbara Rauta de Avelar ${ }^{2}$, Maria Julia Salim Pereira ${ }^{3}$, \\ Adevair Henrique da Fonseca ${ }^{3}$ \\ ${ }^{1}$ Department of Veterinary Medicine, Universidade Federal Espírito Santo, Alto Universitário s/n, Alegre, Brazil; \\ ${ }^{2}$ Course of Veterinary Medicine, Centro de Ciências Agrárias, Universidade Federal Espírito Santo, Seropedica, \\ Brazil; ${ }^{3}$ Department of Animal Parasitology, Veterinary Institute, Universidade Federal Rural do Rio de Janeiro, \\ Seropedica, Brazil
}

\begin{abstract}
A model based on geographical information systems for mapping the risk of fascioliasis was developed for the southern part of Espírito Santo state, Brazil. The determinants investigated were precipitation, temperature, elevation, slope, soil type and land use. Weightings and grades were assigned to determinants and their categories according to their relevance with respect to fascioliasis. Theme maps depicting the spatial distribution of risk areas indicate that over $50 \%$ of southern Espírito Santo is either at high or at very high risk for fascioliasis. These areas were found to be characterized by comparatively high temperature but relatively low slope, low precipitation and low elevation corresponding to periodically flooded grasslands or soils that promote water retention.
\end{abstract}

Keywords: Fasciola hepatica, fascioliasis, epidemiology, geographical information system, Brazil.

\section{Introduction}

Fascioliasis, caused by the trematodes Fasciola hepatica and F. gigantica, is a zoonosis of mainly veterinary interest. It is a major disease in ruminants, which has resulted in considerable economic loss due to mortality, liver condemnation, weight loss, anaemia, lethargy and reduced quality and quantity of milk production (Reid and Dargie, 1995). Over the last decade, the importance of human and animal fascioliasis in various countries of South America has been emphasised. The infection is considered a neglected disease according to the World Health Organization (WHO, 2012) and where animal cases are reported, human cases generally also exist. In South America, Peru and Bolivia are considered to be hyper-endemic for human and animal fascioliasis with other countries such as Chile, Ecuador, Colombia and Venezuela also affected (Fuentes, 2006; Rinaldi et al., 2012). Although the disease has been reported in

\footnotetext{
Corresponding author:

Isabella Vilhena Freire Martins

Department of Veterinary Medicine

Universidade Federal Espírito Santo

Alto Universitário s/n. Caixa postal 16, Alegre, Brazil

Tel. +552835528643

E-mail: isabella@cca.ufes.br
}

humans in many other parts of the world, including several states of Brazil, it has not been recorded in Espírito Santo (Igreja et al., 2004). Epidemiological knowledge about when, where and at what intensity there is risk of infection by F. hepatica is essential for the development of strategic control programmes (Kleiman et al., 2007).

Climatic variables are extremely important to the development of snails that act as intermediate hosts for F. hepatica, and as consequence, to its larval stages. The close relationship between climate and fascioliasis enables the development of models to estimate the risk of occurrence of the disease (Fox et al., 2011). Indeed, modelling the dynamics of fascioliasis in different regions with geographical information systems (GIS) have been used in different countries, assisting in decision-making strategies that mitigate the risk of occurrence of fasciolosis (Malone et al., 1998; Yilma and Malone, 1998; Tum et al., 2004; Dutra et al., 2010; McCann et al., 2010). GIS can also be used as an auxiliary tool when building models to estimate endemic, disease-free and potential dispersion areas of diseases. Its use is especially important in areas and types of events for which data are not available and where the development of disease control strategies requires modelling (Yang et al., 2005).

Although fascioliasis in ruminants is prevalent in 
several Brazilian states, epidemiological information on the disease in these areas is still insufficient (Dutra et al., 2010). The disease has only recently been recorded in Espírito Santo, a southern state of Brazil, with a growing trend of observed fascioliasis in cattle at slaughter with an average prevalence of $24.9 \%$ during the years 2006-2009 (Bernardo et al., 2011). Alves et al. (2011) reported the distribution and factors associated with fascioliasis in cattle in 10 municipalities of the southern part of Espirito Santo between 2008 and 2009.

Epidemiological analysis of human and animal fascioliasis has been carried out with GIS in different parts of the world (Malone et al., 1992; Yilma and Malone, 1998; Fuentes et al., 2001; Tum et al., 2004; Fuentes, 2006), including Brazil (Dutra et al., 2010). It was felt that this approach would be useful in the geographical context of Espirito Santo, as there is an increase of fascioliasis in the state and the determinants involved in the dynamics of the disease are still unknown. Assessment of the role of determinants responsible for the onset and prevalence of this parasitic disease are needed for this region. Thus, the objective of this study was to identify the determinants and analyse the risk of occurrence of fascioliasis in Espírito Santo, using a geo-environmental analysis system.

\section{Material and methods}

\section{Study area}

The current study focusses on the southern part of Espírito Santo situated between latitudes $20^{\circ} 27^{\prime} \mathrm{S}$ and $21^{\circ} 03^{\prime} \mathrm{S}$ and longitudes $41^{\circ} 00^{\prime} \mathrm{W}$ and $41^{\circ} 78^{\prime} \mathrm{W}$, which represents zone 24 according to the universal transverse Mercator (UTM) geographic coordinate system. Its grid position 204,217-309,154 m W, $7,642,859-7,760,032 \mathrm{~m} \mathrm{~S}$ comprises an area of approximately 900,000 ha (Fig. 1). The climate in the region is described by the Brazilian Institute of Geography and Statistics (IBGE, 2008) as predominantly humid and subtropical, with high annual precipitation. The topography is dominated by plains and mountainous areas with numerous streams.

\section{Analytic approach}

The modules "create", "assessment" and "environmental signature" of the Geo-environmental Analysis System (Vista Saga, 2007) from the Federal University of Rio de Janeiro (LAGEOP, 2007) were used to cre- ate the dataset and the analyses. A bibliographic survey on the major factors involved in the fascioliasis epidemiology was done and the factors deemed relevant selected. The determinants were subjectively weighted according to their perceived relative importance (Table 1) before combining them for the construction of the fascioliasis risk-map.

For each determinant, a digital theme map was created in raster format based on theme maps in tiff format of Espírito Santo provided by Instituto Estadual do Meio Ambiente (IEMA), i.e. the State Environmental Institute. Together they formed a $150 \mathrm{x}$ $150 \mathrm{~km}$ rectangle at $25 \times 25 \mathrm{~m}$ resolution, totalling 36,000,000 pixels, georeferenced in UTM, datum SAD 69 (IBGE, 2005). The theme maps for temperature and precipitation correspond to the historical averages of the last 30 years. The determinant "bydrography", although graded as relevant on its own, was represented in conjunction with land use given that the $1: 25 \mathrm{~m}$ scale necessary to represent the study area could not portray details important for the occurrence of fascioliasis in a theme map, e.g. small

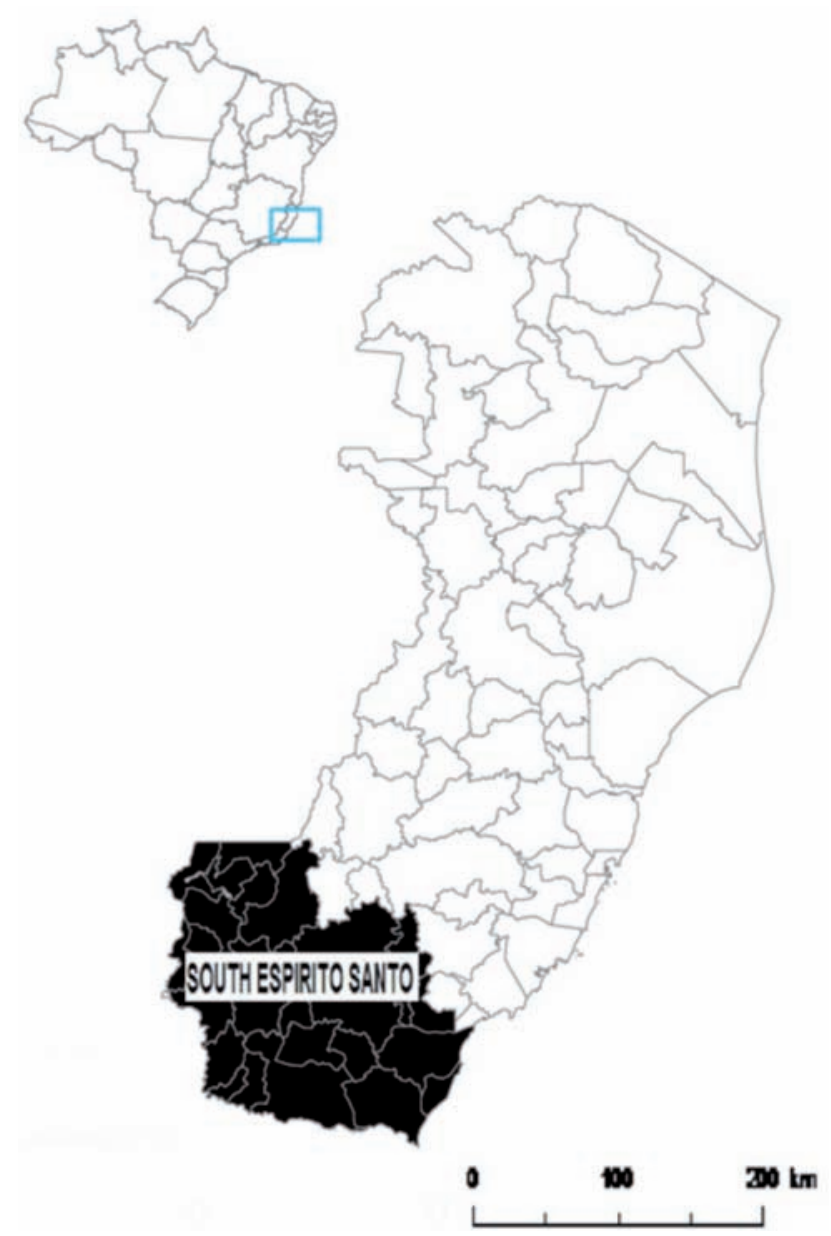

Fig. 1. The situation of the study area in the state of Espírito Santo and in Brazil. 
Table 1. Weigths and grades assigned to the epidemiological status of Fasciola hepatica.

\begin{tabular}{|c|c|c|c|c|}
\hline \multirow{2}{*}{ Determinant } & \multirow{2}{*}{ Weight } & \multicolumn{3}{|c|}{ Category } \\
\hline & & $8-10$ & $4-7$ & $1-3$ \\
\hline Land use & $24 \%$ & Pasture/wetland & - & Forest/agriculture/urban \\
\hline Altitude & $19 \%$ & $<800 \mathrm{~m}$ & $800-1,700 \mathrm{~m}$ & $>1,700 \mathrm{~m}$ \\
\hline Slope & $19 \%$ & $<0 \%$ & $10-15 \%$ & $>15 \%$ \\
\hline Rainfall & $17 \%$ & $<1,600 \mathrm{~mm} /$ year & $>1,600 \mathrm{~mm} /$ year & - \\
\hline Soil type & $13 \%$ & Alluvials/podzol & Latosol/podzol & Brunizem/cambisol* \\
\hline Temperature & $8 \%$ & $15-25^{\circ} \mathrm{C}$ & $10-14.9$ and $>25^{\circ} \mathrm{C}$ & $6-9.9^{\circ} \mathrm{C}$ \\
\hline
\end{tabular}

* Soils with incipient soil formation

streams, wetlands and irrigated areas discussed by other authors (Tum et al., 2004; Durr et al., 2005; Kleiman et al., 2007).

For the assessment of fascioliasis risk, weightings were assigned to determinants according to their assumed relevance to the occurrence of the disease. Categories not used in the analysis, but present on the maps, were blocked. Relevance grades ranging from 1 (low) to 10 (high) were assigned to the determinants (Table 1). Risk areas, obtained through the assessment process and represented by grades, were classified and grouped into the following categories: low risk (grades 1-4), moderate risk (5-6), high risk (7-8) and very high risk (9-10). The representative risk-map was submitted to signature and the results presented and discussed.

\section{Results}

Theme maps of the risk factors associated with fascioliasis used in the analyses are shown in Fig. 2, and the spatial distribution of the risk areas in southern Espírito Santo is shown in Fig. 3. The results indicate that over $50 \%$ of southern Espírito Santo is either at high or at very high risk for fascioliasis (Table 2).

The results of the signatures carried out on the rep-
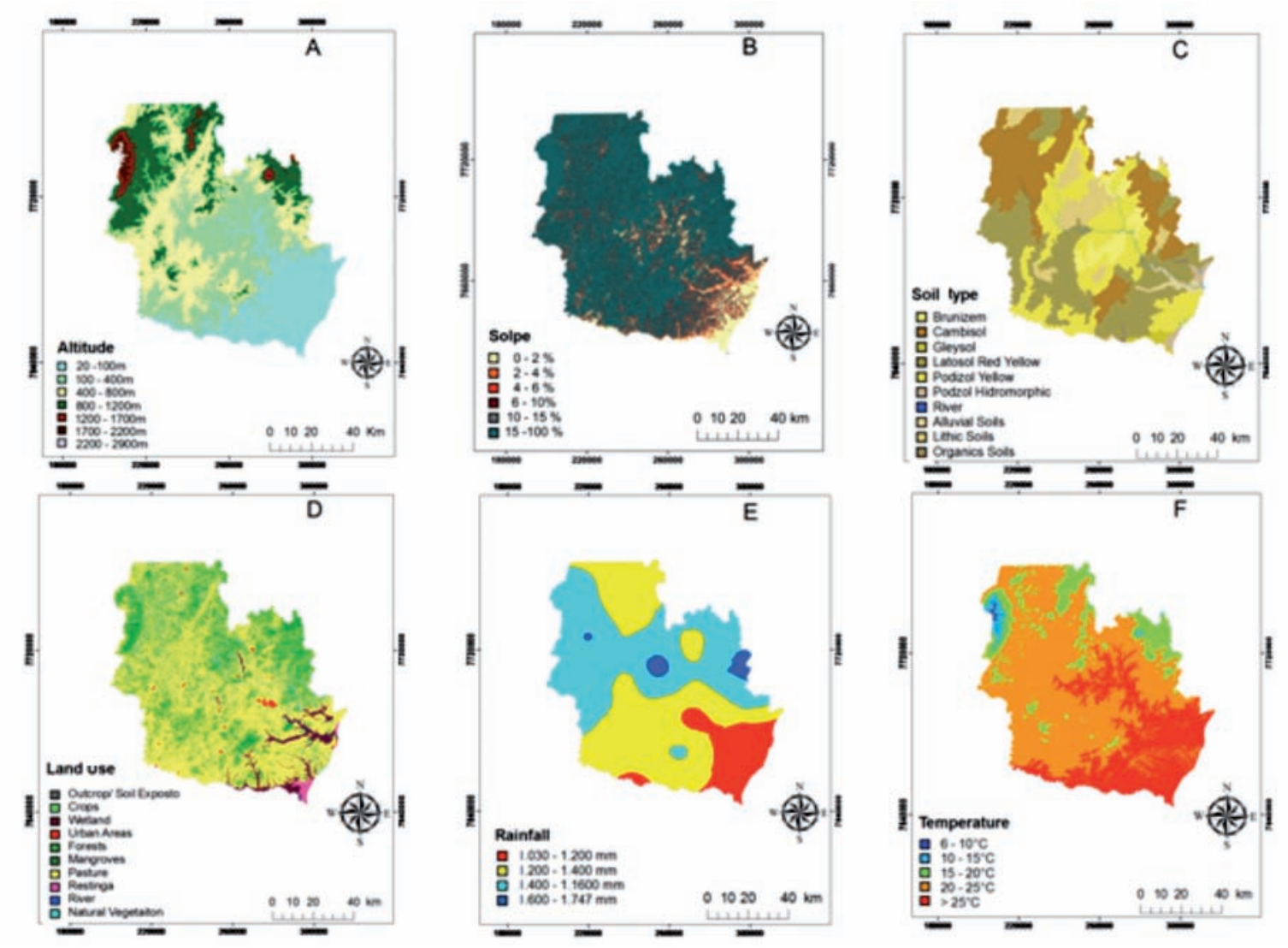

Fig. 2. Theme maps: land use (A); slope (B); rainfall (C); altitude (D); soil type (E) and temperature (F). 


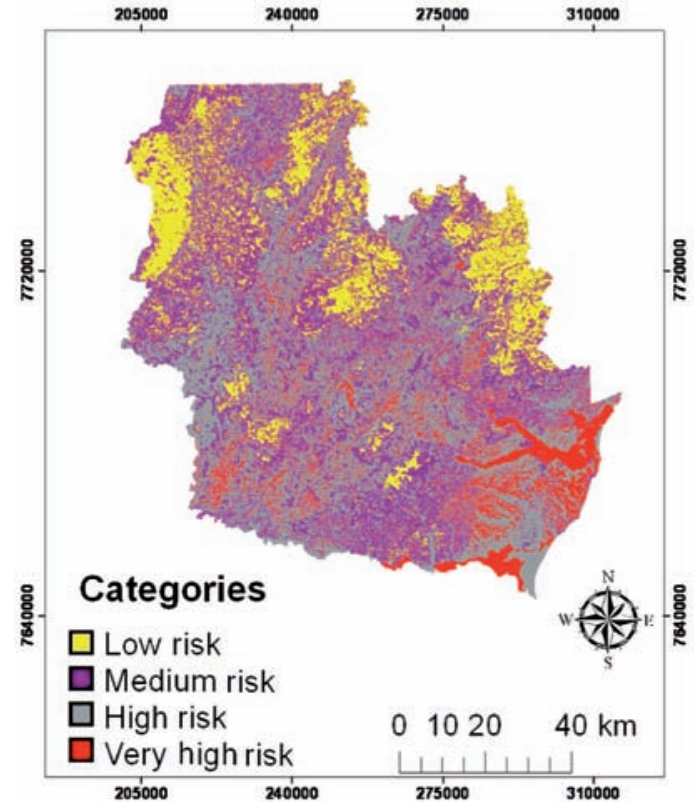

Fig. 3. The distribution of risk for fascioliasis in South Espírito Santo, Brazil.

Table 2. Size of the different risk areas for fascioliasis in South Espírito Santo, Brazil.

\begin{tabular}{lcc}
\hline Risk category & Area $(\%)$ & Area (ha) \\
\hline Low risk & 16.1 & 145,937 \\
Medium risk & 29.1 & 263,257 \\
High risk & 47.4 & 429,151 \\
Very high risk & 7.4 & 66,906 \\
\hline
\end{tabular}

resentative risk-maps per municipality in southern Espírito Santo are shown in Table 3. The geography of three of the municipalities with $>80 \%$ area in the high and the very high risk categories is dominated by grassland: Itapemirim $(64.7 \%)$, Marataízes $(67.9 \%)$ and Presidente Kennedy (69.3\%). In addition, Itapemirim and Presidente Kennedy consist of 39\% and 29\% wetlands, respectively. The signature carried out on the land use showed that $77 \%$ of the areas assigned very high-risk consist of grassland and $22 \%$ of wetlands.

In this study, over $90 \%$ of the areas assigned very high-risk were found at elevations up to $400 \mathrm{~m}$ above the mean sea level (MSL); 100\% when including elevations up to $800 \mathrm{~m}$. The municipalities of Iuna, Ibitirama, Dores do Rio Preto and Divino de São Lourenço are situated at higher elevations, with $100 \%$ of the areas above $400 \mathrm{~m}$. In addition, $80 \%$ of Ibitirama, Dores do Rio Preto and Divino de São Lourenço are above the $800 \mathrm{~m}$ elevation line.

The slopes of the areas assigned very high-risk were shown to vary up to $15 \%$ with $89 \%$ of the land characterized by slopes at $6 \%$ or lower. These areas also presented average temperatures above $20{ }^{\circ} \mathrm{C}$ with $68 \%$ having temperatures between $20^{\circ} \mathrm{C}$ and $25^{\circ} \mathrm{C}$.

The soil types in the areas assigned very high risk are latosol (23.9\%), podzol (34.6) and alluvial (15.3\%). Latosol (oxisol) soils usually have high permeability and are composed of minerals at an advanced stage of weathering, while podzol (ultisol) has lower permeability. Alluvial (fluvisol) soils, consisting of alluvial

Table 3. Fascioliasis risk in South Espírito Santo state, Brazil, stratified by city*.

\begin{tabular}{|c|c|c|c|c|}
\hline City & Low risk & Medium risk & High risk & Very high risk \\
\hline Alegre & 9.85 & 30.67 & 54.49 & 4.99 \\
\hline Apiacá & 2.33 & 19.90 & 69.17 & 8.60 \\
\hline Atilio Vivacqua & 2.35 & 23.06 & 65.27 & 9.31 \\
\hline Bom Jesus do Norte & 0.31 & 18.41 & 72.51 & 8.77 \\
\hline Cachoeiro de Itapemirim & 9.96 & 26.74 & 56.99 & 6.31 \\
\hline Castelo & 27.64 & 37.42 & 33.19 & 1.75 \\
\hline Divino de São Lorenço & 37.35 & 36.75 & 25.90 & 0.00 \\
\hline Dores do Rio Preto & 30.44 & 44.89 & 24.67 & 0.00 \\
\hline Guaçui & 7.53 & 28.91 & 63.54 & 0.02 \\
\hline Ibatiba & 19.89 & 42.81 & 35.46 & 1.84 \\
\hline Ibitirama & 45.79 & 37.32 & 16.71 & 0.19 \\
\hline Irupi & 22.86 & 40.33 & 35.93 & 0.89 \\
\hline Itapemirim & 0.75 & 11.40 & 54.09 & 33.77 \\
\hline Iuna & 31.40 & 40.36 & 26.45 & 1.78 \\
\hline Jerônimo Monteiro & 1.17 & 21.80 & 68.34 & 8.68 \\
\hline Marataizes & 0.02 & 6.28 & 57.80 & 35.90 \\
\hline Mimoso do sul & 6.03 & 30.85 & 57.08 & 6.04 \\
\hline Muniz Freire & 29.70 & 36.87 & 31.80 & 1.64 \\
\hline Muqui & 5.30 & 23.26 & 63.09 & 8.35 \\
\hline Presidente Kennedy & 1.15 & 13.01 & 64.57 & 21.26 \\
\hline Rio Novo do Sul & 18.86 & 38.55 & 39.77 & 2.82 \\
\hline São José do Calçado & 5.02 & 18.50 & 65.23 & 11.25 \\
\hline Vargem Alta & 55.74 & 33.69 & 10.44 & 0.13 \\
\hline
\end{tabular}

\footnotetext{
*All values are percentage.
} 
sediments, indicate areas where there is risk of flooding (EMBRAPA, 2006). The two first mentioned soil types account for $58 \%$ of all soils in the region. They have no particular water retention characteristics but may eventually turn into clay, thereby facilitating water retention.

\section{Discussion}

The modelled spatial distribution of fascioliasis risk in southern Espírito Santo indicates that $50 \%$ of the study area is at high or a very high risk for fascioliasis. Moreover, no cases of fascioliasis have been discovered in many municipalities situated in the other half of the land shown to have low or moderate risk (Alves et al., 2011), highlighting the good relationship between the model and the data gathered from farms in the region.

The signature carried out on the land use map showed that $77 \%$ of the areas of very high-risk are grasslands while $22 \%$ are wetlands, supporting the study by Tum et al. (2004), who identified these areas as being at high risk of fascioliasis due to $F$. gigantica.

In this study, over $90 \%$ of the areas assigned a very high-risk was situated at elevations up to $400 \mathrm{~m}$ above sea level reaching $100 \%$ when including elevations up to $800 \mathrm{~m}$. These results are similar to those by Tum et al. (2004), working with F. gigantica and by Dutra et al. (2010), working with $F$. hepatica, who assigned areas as high-risk up to $400 \mathrm{~m}$ and low-risk above $1,200 \mathrm{~m}$. Few studies have reported the presence of fascioliasis foci in areas situated at high elevation. For example, although Bennema et al. (2011) failed to find a significant relationship between elevation and risk of infection, they felt that a majority of reports support a negative relationship between elevation and infection risk. However, isolated endemic areas of human fascioliasis have been observed in the Bolivian Altiplano from 3,800-4,100 $\mathrm{m}$ above sea level (Fuentes et al., 2001). Infection by $F$. hepatica in areas up to $2,560 \mathrm{~m}$ above sea level in Ethiopia has also been documented by Yilma and Malone (1998), who argued that the parasite cycle is longer at higher elevations, a fact Malone et al. (1998) and McCann et al. (2010) agreed with. Thus, the fact that $80 \%$ of Ibitirama, Dores do Rio Preto and Divino de São Lourenço lie above 800 $\mathrm{m}$ elevation, does not necessarily contradict their status as areas carrying risk for fascioliasis.

In the study area, $100 \%$ of the area had slopes of up to $15 \%$. Similarly, McCann et al. (2010) documented a negative relationship between slope, soil $\mathrm{pH}$ and the spatial distribution of $F$. hepatica, arguing that slope may influence the life cycle of the parasite as strong slopes are less suitable to the intermediate host due to their increased drainage. Moreover, these authors claimed that slope may interfere with the vegetation cover, land use and soil type and thus have a negative effect on the snails. However, Bennema et al. (2011) found a positive relationship between slope and infection risk, which they attributed to small streams and water collections forming at the base of the hills.

Annual precipitation of up to $1,400 \mathrm{~mm}$ was observed in over $95 \%$ of the areas assigned a very highrisk. Although precipitation is a risk factor of for fascioliasis, there is no consensus on optimum precipitation levels. Rapsch et al. (2008) considered monthly precipitation of up to $90 \mathrm{~mm}$ as the maximum risk of occurrence of fascioliasis, which corresponds to an annual precipitation of $1,200 \mathrm{~mm}$. According to these authors, the risk of infection decreases rapidly above $210 \mathrm{~mm}$ per month (2,500 $\mathrm{mm}$ annually). However, other authors argue that risk is higher in areas with high annual precipitation, moist soils and surplus water (McCann et al., 2010; Fox et al., 2011). Since Rapsch et al. (2008) attribute the transmission in arid areas to irrigation, rainwater collections and floods, the determinant precipitation alone may be a poor explanatory factor (Durr et al., 2005; Bennema et al., 2011).

Soil moisture has been identified as a key factor in determining year-to-year variation in the transmission of F. hepatica (Malone et al., 1984). The most favourable soils are those with high water retention capacity such as alluvial soils (Rapsch et al., 2008) and the transmission of the disease is being associated with poorly drained soils (Malone et al., 1992; Bennema et al., 2011) or loam soils (Charlier et al., 2011). McCann et al. (2010) also found that soils with thin layers of sand were positively associated with infection by $F$. hepatica due to their poor drainage capacity. However, vegetation cover may influence water retention by retaining soil moisture, thereby supporting transmission even in permeable soil types such as latosols and podzols.

All very high-risk areas presented average temperatures above $20{ }^{\circ} \mathrm{C}$. Although Dutra et al. (2010) dismissed temperature as a relevant determinant for fascioliasis, they claimed that temperatures in the range of $10-25^{\circ} \mathrm{C}$ would be ideal for the growth of the snails that act as intermediate hosts for the fascioliasis parasite. In contrast, Malone et al. (1998), working with F. hepatica and F. gigantica in Africa, argued that annual average temperatures above $23{ }^{\circ} \mathrm{C}$ represents the limit for maintaining the life cycle in the former snail species. This does not contradict the reported 18 ${ }^{\circ} \mathrm{C}$ optimum temperature for growth of the parasite, 
but more studies on the relevance of temperature for the upper limit are warranted.

Although some studies (Dutra et al., 2010; Fox et al., 2011) argue that temperature and precipitation are the main determinants of Fasciola transmission efficiency, this is not always the case. While rainfall was a consistent predictor of infection in the many models developed by McCann et al. (2010) for the UK where the climate is temperate, the temperature was a predictor in five of them. On the other hand, as done in the model developed by Tum et al. (2004) for fascioliasis due to F. gigantica in Cambodia, temperature and precipitation were excluded, the former because it fluctuates little throughout the year, and the latter because they observed that flooding in the study area was rather caused by melting snow than local rainfall. This fact confirms the hypothesis that the determinants of fascioliasis risk vary with location and that risk factors may interact, e.g. in the UK, temperature had greater impact in areas where average temperature was above $10{ }^{\circ} \mathrm{C}$ and there was no rain shortage (Fox et al., 2011). In addition, these authors reported that in areas of high temperature and low precipitation, low soil moisture directly influenced snail development negatively. In Belgium, elevation, slope and soil type were not relevant with only precipitation and management practices being significant predictors (Bennema et al., 2011). The importance of management as a variable explaining the variation in the spatial distribution of $F$. hepatica in dairy farms has also been reported by Charlier et al. (2011). Although management systems were not evaluated in this study for lack of data, farm visits by other researchers have sometimes shown management problems such as grazing in areas suitable for the intermediate host snails (Alves et al., 2011).

\section{Conclusions}

Notably, risk factors of fascioliasis vary with geography and climate, factors that directly affect transmission of the disease. The use of GIS tools for the epidemiological study of fascioliasis enables the classification of risk areas and the development of control strategies. In this study, areas at higher risk were characterised by comparatively high temperature and low slope, precipitation and elevation. These areas correspond to periodically flooded grasslands, or with soils that promote water retention and are therefore suitable for the growth of the intermediate snail host.

Epidemiological data for fascioliasis in Brazil are still insufficient and we believe that the different abi- otic and biotic factors require individualized studies. Therefore, studies on the spatio-temporal variation of the disease are essential for monitoring the transmission patterns in different regions.

\section{Acknowledgements}

This research was supported by CAPES (Coordination for the Improvement of Higher Education Personnel) - PROCAD n $093 / 2007$.

\section{References}

Alves DP, Carneiro MB, Martins IVF, Bernardo CC, Donatele DM, Pereira Júnior OS, Almeida BR, Avelar BR, Leão AGC, 2011. Distribution and factors associated with Fasciola hepatica infection in cattle in the south of Espírito Santo State, Brazil. J Venom Anim Toxins 17, 271-276.

Bennema SC, Ducheyne E, Vercruysse J, Claerebout E, Hendrickx G, Charlier J, 2011. Relative importance of management, meteorological and environmental factors in the spatial distribution of Fasciola hepatica in dairy cattle in a temperate climate zone. Int J Parasitol 41, 225-233.

Bernardo CC, Carneiro MB, Avelar BR, Donatele DM, Martins IVF, Pereira MJS, 2011. Prevalence of liver condemnation due to bovine fasciolosis in Southern Espírito Santo: temporal distribution and economic losses. Rev Bras Parasitol Vet 20, 4953.

Charlier J, Bennema SC, Caron Y, Counotte M., Ducheyne E, Hendrickx G, Vercruysse J, 2011. Towards assessing fine-scale indicators for the spatial transmission risk of Fasciola hepati$c a$ in cattle. Geospat Health 5, 239-245.

Durr PA, Tait N, Lawson AB, 2005. Bayesian hierarchical modeling to enhance the epidemiological value of abattoir surveys for bovine fasciolosis. Prev Vet Med 71, 157-172.

Dutra LH, Molento MB, Naumann CRC, Biondo AW, Fortes FS, Savio D, Malone JB, 2010. Mapping risk of bovine fasciolosis in the south of Brazil using geographic information systems. Vet Parasitol 169, 76-81.

EMBRAPA, 2006. Centro Nacional de Pesquisa de Solos. Sistema brasileiro de classificação de Solos. 2 ed. Rio de Janeiro: Embrapa Solos.

Fox NJ, White PCL, McClean CJ, Marion G, Evans A, Hutchings MR, 2011. Predicting impacts of climate change on Fasciola hepatica risk. PLoS One 6, 1, e16126.

Fuentes MV, 2006. Remote sensing and climate data as a key for understanding fasciolosis transmission in the Andes: review and update of an ongoing interdisciplinary project. Geospat Health 1, 59-70.

Fuentes MV, Malone JB, Mas-Coma S, 2001. Validation of a mapping and prediction model for human fasciolosis transmission in Andean very high altitude endemic areas using 
remote sensing data. Acta Trop 79, 87-95.

IBGE, Produção Pecuária Municipal. 2008. Available at: http://www.ibge.gov.br/home/estatistica/economia/ppm/2008/ defaulttabzip.shtm (accessed on February 2011).

IBGE, Resolução do Presidente do IBGE No 1/2005. Available at: $\mathrm{ftp} / / / g e o f t p . i b g e . g o v . b r / d o c u m e n t o s / g e o d e s i a / p r o j e t o \_m u d a n c a$ _referencial_geodesico/legislacao/rpr_01_25fev2005.pdf. (accessed on July 2012).

Igreja RP, Barreto MGM, Soares MS, 2004. Fascioliasis: report of two cases from rural areas of Rio de Janeiro. Rev Soc Bras Med Trop 37, 416-417.

Kleiman F, Pietrokovsky S, Prepelitchi L, Carbajo AE, Wisnivesky-Colli C, 2007. Dynamics of Fasciola hepatica transmission in the Andean Patagonian valleys, Argentina. Vet Parasitol 145, 274-286.

LAGEOP, Laboratório de Geoprocessamento/UFRJ. 2007. Available at: http://www.lageop.ufrj.br/downloads.php (acessed on February 2011)

Malone JB, Fehler DP, Loyacano AF, Zukowski SH, 1992. Use of Landsat MSS imagery and soil type in a geographical information system to assess site specific risk of Fasciola on Red River basin farms in Louisiana. Ann NY Acad Sci 653, 389-397.

Malone JB, Gommes R, Hansen J, Yilma JM, Slingenberg J, Snijders F, Nachtergaele F, Ataman E, 1998. A geographic information system on the potential distribution and abundance of Fasciola hepatica and Fasciola gigantic in East Africa based on Food and Agriculture Organization databases. Vet Parasitol 78, 87-101.

Malone JB, Loyacano, AF, Hugh-Jones ME, Corkum KC, 1984. A three year study on seasonal transmission and control of Fasciola hepatica of cattle in Louisiana. Prev Vet Med
3, 131-141.

McCann CM, Baylis M, Williams DJL, 2010. The development of linear regression models using environmental variables to explain the spatial distribution of Fasciola hepatica infection in dairy herds in England and Wales. Int J Parasitol 40, 10211028.

Rapsch C, Dahinden T, Heinzmann D, Torgerson PR, Braun U, Deplazes P, Hurni L, Bar H, Knubben-Schweizer G, 2008. An interactive map to assess the potential spread of Lymnaea truncatula and the free-living stages of Fasciola hepatica in Switzerland. Vet Parasitol 154, 242-249.

Reid JFS, Dargie JD, 1995. Como os estágios adultos de Fasciola hepatica afetam a saúde e a produtividade do bovino. Hora Vet 15, 23-26.

Rinaldi L, Gonzalez S, Guerrero J, Aguilera LC, Musella V, Genchi C, Cringoli G, 2012. A One-Health integrated approach to control fascioliasis in the Cajamarca valley of Peru. Geospat Health 6, S67-S73.

Tum S, Puotinen ML, Copemanc DB, 2004. A geographic information systems model for mapping risk of fasciolosis in cattle and buffaloes in Cambodia. Vet Parasitol 122, 141-149.

Yang GJ, Vounatsou P, Zhou XN, Utzinger J, Tanner M, 2005. A review of geographic information system and remote sensing with applications to the epidemiology and control of schistosomiasis in China. Acta Trop 96, 117-129.

Yilma JM, Malone JB, 1998. A geographic information system forecast model for strategic control of fasciolosis in Ethiopia. Vet Parasitol 78, 103-127.

WHO, 2012. Neglected tropical diseases. Available at: http://www.who.int/neglected_diseases/integrated_media/integrated_media_fascioliasis/en/ (accessed on July 2012). 